\title{
Effect of Medication Safety Education Program on Intensive Care Nurses' Knowledge regarding Medication Errors
}

\author{
Imad Abukhader*, Khadija Abukhader \\ Faculty of Nursing, Arab American University, Jenin, Palestine \\ Email: *imad.abukhader@aaup.edu
}

How to cite this paper: Abukhader, I. and Abukhader, K. (2020) Effect of Medication Safety Education Program on Intensive Care Nurses' Knowledge regarding Medication Errors. Journal of Biosciences and Medicines, 8, 135-147.

https://doi.org/10.4236/jbm.2020.86013

Received: May 8, 2020

Accepted: June 8, 2020

Published: June 11, 2020

Copyright $\odot 2020$ by author(s) and Scientific Research Publishing Inc. This work is licensed under the Creative Commons Attribution International License (CC BY 4.0).

http://creativecommons.org/licenses/by/4.0/

\begin{abstract}
Background: Medication errors are the iceberg of patient safety in hospitals and leading cause of morbidity and mortality among patients. Objectives: The study aim was to evaluate the effect of an educational program of medication safety on the knowledge of critical care nurses regarding intravenous medication errors. Methods Design: There are one group pretest and posttest designs. Subject: A convenient sample of all registered nurses (52) works in Palestine Medical Complex. Data collection tools: A self-administered knowledge determination questionnaire consists of both qualitative and quantitative statements to measure level of knowledge, used as data collection tool in pre and post educational sessions, with educational booklet as intervention tool. Statistical analysis: Data were analyzed with Statistical Package for the Social Sciences Software Version 18. The results are presented as frequency \& percentage as appropriate at alpha level of $\mathrm{P}<0.05$; inferential statistics were generated. Paired t-test was used to perform the comparisons. Results: There was statistically significant difference in the knowledge level for the intensive care unit's nurses regarding the intravenous medication administration during pre and post education program. Statistical analysis showed that there was a statistically significant between age, educational degree, critical units/wards, years of nursing experience and previous medication administration education program of the nurses and their knowledge during different phases of program intervention. Conclusion: Educational program on medication safety improves the knowledge of critical care nurses regarding intravenous medication errors. This study recommends that medication errors should be periodically assessed by improving clinical guidelines of medication administration.
\end{abstract}




\section{Keywords}

Medication Error, Nursing Knowledge, Medication Administration, Educational Program

\section{Introduction and Background}

Patient safety is a priority for numerous health organizations worldwide, and is a corner stone in providing a high quality of care, whereas medication is an integral component of patient safety and has been considered as a major indicator of healthcare quality [1] [2] [3]. Medication error refers to any preventable event that may cause or lead to inappropriate medication use or patient harm [1].

Medication errors lead to an increase in the duration of hospitalization and disability and death in up to $6.5 \%$ of hospital admissions [1] [3] [4].

In the Intensive Care Units (ICUs), hospitalized patients receive more drugs than patients in other units. Because of drowsiness or unconsciousness, ICU patients are not able to monitor and report the drug side effects: thus, in this unit, patients are most vulnerable to be exposed to medication errors due to care complexity, severe illness, and providing life-sustaining treatment [5] [6]. On average, ICU patients are exposed to 1.7 errors per day and medication errors account for $78 \%$ of life threatening errors. Intensities of medication errors are minor, severe, and life-threatening leading to death [6] [7].

Medication errors are among the most frequent types of incidents in critically ill patients, and are more common in the prescription and administration stages. Although most such incidents have no clinical consequences, a significant percentage is proved harmful for the patient, and a large proportion is avoidable [6] [7] [8].

A systematic review describing medication errors in Middle Eastern countries, reported that the studies related to medication errors were relatively few in number, and highlighted that poor knowledge of medicines was a contributory factor in both prescribers and nurses administering drugs. For that, these countries urgently need to introduce educational programs for improving knowledge of nurses to improve their quality of drug administration [9].

In Palestine little is known about the prevalence of medication errors. In fact, this study is the first in the field of nursing which concerns about the medication errors and safety practices of nurses working at the intensive care units. Also study findings are to be utilized to support health care providers and health policy makers to adopt and implement evidence based interventions such as educational programs or training curriculum to reduce medication errors and promote patients' safety [10]. Therefore, the purpose of this study aimed to evaluate the effect of medication administration safety education program on knowledge level of intensive care unit nurses regarding intravenous medication safety. 


\section{Material and Methods}

Design: A quasi-experimental study, one group pretest and posttest design.

Setting: The study was conducted in intensive care units of four hospitals known as Palestinian Medical Complex in Ramallah city, West bank, Palestine.

Sample: Out of the 214 nurses who were working in the four hospitals, a convenient sample of all registered nurses (52) working in intensive care units of four hospitals were included who were working at the medical intensive care unit (ICU), the surgical ICU and the Coronary Care Unit (CCU).

Data collection tools: A self-administered Knowledge determination questionnaire used as data collection tools in pre-educational and post-educational evaluation. The questionnaire was developed by researchers based on the literature to evaluate the nurses' knowledge on intravenous medication safety.

The first part of the questionnaire included the sociodemographic information such as age, gender, education qualifications, unit/department, position, work experience, having medication administration program. The second part contained 16 items comprised of both qualitative and quantitative statements to measure level of nurse's knowledge regarding intravenous medication safety \& errors, where eight statements focused on clinical guidelines of medication preparation and the other (eight statements) addressed the eight rights of IV medication administration.

The qualitative-type statements assessed the level of nurse's knowledge regarding maintenance of quality in practice as well as clinical decision-making skills, while the quantitative-type statements tested the nurse's knowledge level on calculation and dosing skills.

Each statement has True, False and Don't Know responses for the respondents to correctly choose.

Face and content validity of the questionnaire was determined by panel of experts at Hacettepe University, where their feedback of small changes were incorporated into the questionnaire prior to implementation.

Reliability of questionnaire verified through piloting the developed questionnaire for 1 month at the specialized surgical hospital of Bethlehem Arab Rehabilitation Society, Bethlehem, West bank, where test-retest method was used, the correlation coefficients between the two turns answering the questions in working registered nurses were 85.0 and 90.0 respectively.

Intervention tool: Educational Booklet on safe medication administration among intensive care units' nurses. The booklet was developed by the researchers based on related literature review, desktop work and revising related resources materials.

The education booklet contained different section and addresses the main following medication safety and errors related themes: such as International patient safety goals, the eight rights of medication administration, Overview of policy and procedure guideline of medication administration, Rules of medication administration, Calculation of IV adult medication dose, High alert medica- 
tion, Medication sensitivity, Classification of medication errors, Common factors of medication errors, Strategies of managing medication errors, Signification barriers to medication errors reporting and Aspects of working conditions in relation to medication administration safety.

Content validity for the education booklet was assessed by 3 experts in academic nursing fields and two experts from the nursing staff from the hospital of the study.

Ethical Consideration: The Research Ethical Committee at Hacettepe University approved the study (16969557-374). Written informed consent through a cover letter was obtained from participants. Participants confided that the information would remain confidential. Additionally, the participants were free to withdraw from the study anytime.

\section{Methods of Data Collection}

\subsection{Pilot Study}

A pilot study conducted for 1 month on $10 \%$ of total number of the study sample (five registered nurses) working at intensive care unit at the specialized surgical hospital of Bethlehem Arab Rehabilitation Society, West bank. The purpose of the pilot study was to test the clarity and reliability of the study tool (knowledge determination questionnaire). Appropriate little modifications on the study tool were made after analyzing the pilot data before the actual data collection.

\subsection{Data Collection Procedure}

Data were collected during the period April 2016 to August 2016 through different study phases.

\subsection{Pre Intervention Phase}

Pre-assessment for the targeted registered nurses' knowledge about intravenous medication administration errors was done by using the self-administered knowledge determination questionnaire, which started on April 2016 and lasted for one month.

Also this phase was necessary to gain insight on the situation of the intensive care unit facilities and resources as important step before going to implement the nursing educational program of medication safety as well as cooperation and accessibility of study subjects which were assessed during this phase.

\subsection{Intervention/Implementation Phase}

This phase consisted of specific dynamic iterative activities designed to put the nursing educational program of medication safety booklet into actions effectively. The content of nursing education booklet was distributed for the intensive care unit registered nurses (52) divided into two groups, among 2 sessions for each subgroup separately, duration for each session was estimated about $60 \mathrm{mi}-$ 
nutes approximately, during the morning shift, one session every week, in seminar room in the hospital, and the total allocated time for achieving the whole program to all study sample was 4 hours ( 2 sessions $\times 60 \mathrm{~min} \times 2$ groups) lasted for 2 months. It took over a period from May to the middle of June 2016.

Collaborative lectures with power point presentation, group discussion, demonstration using the audiovisual aids such as video film and brain storming were used as learning methods during each session.

\subsection{Post Intervention Phase/Evaluation}

In this last phase, post-assessment for the targeted registered nurses' knowledge about intravenous medication administration errors were done two weeks after the educational session, by using the same self-administered knowledge determination questionnaire to evaluate the effect of implementation of the medication administration safety education program on knowledge level of intensive care unit nurses regarding intravenous medication safety started on July 2016 and lasted for one month.

\subsection{Statistical Analysis}

The Statistical Package for the Social Sciences software version 18.0 (SPSS inc., Chicago, IL, USA) was used for data analysis. Descriptive statistics (Frequency and percentage) were used for numerical data and other data such as gender, age category, education qualification, years of experience... etc. Comparison of the critical nurse's knowledge was done using paired t-test to compare the means before and after implementation of nursing medication administration safety education program and to determine any significant differences between variables where inferential statistics were generated at alpha level of $\mathrm{P}<0.05$.

\section{Results}

52 nurses were included in this study and completed the pre \& post questionnaire with $100 \%$ response rate. As shown in Table 1 the majority $53.8 \%$ of the studied samples were males, and $48.1 \%$ have age equals or less than 25 years old. The majority of the samples were holding bachelor degree in nursing; $90.4 \%$ and only $9.6 \%$ of the nurses held a master degree in nursing. Regarding years of experience in nursing field, the majority $67.3 \%$ of the study sample have equal or less than 5 years of experience, while the minority of the studied nurses (9.6\%) have experience equals or more than 11 years. $44.2 \%$ of the study subjects are working at the medical ICU, and the remaining $30.8 \% \& 25 \%$ are working at the surgical ICU and CCU respectively.

Table 2 showed that the results of this study indicated that only $53.8 \%$ of the intensive care nurses had satisfactory knowledge score pre-test about the International Patient Safety Goals where this percentage was improved to have an increased satisfactory level after receiving the educational booklet and related sessions as more than (92.3\%) had satisfactory knowledge. Regarding the guidelines 
of IV medications administration, 58\% of the study subjects had satisfactory knowledge score pre-test which has improved after educational booklet to $96.2 \%$ who have satisfactory knowledge. In term of nurses' knowledge of eight rights of medication administration, although the majority of the critical care nurses (88.5\%) had unsatisfactory knowledge as pretest score, which has improved after the educational booklet introduction and related sessions where $92.3 \%$ of the critical nurses had satisfactory knowledge post test score.

Although the majority of the critical care Nurses had unsatisfactory knowledge on the eight rights of medication administration, but their level of knowledge was satisfactory on separate right with variation among the different Eight rights, indeed the level of knowledge improved later to the education booklet and related educational sessions on the eight rights as whole and on the specific right that tended to have Low knowledge such as right reason and right response (Table 3).

Table 1. Demographic characteristics of the study subjects $(n=52)$.

\begin{tabular}{|c|c|c|}
\hline Demographic characteristics & $\mathrm{n}$ & $\%$ \\
\hline \multicolumn{3}{|c|}{ Age: } \\
\hline$\leq 25$ years & 25 & 48.1 \\
\hline $26-30$ years & 21 & 40.4 \\
\hline$\geq 31$ & 6 & 11.5 \\
\hline \multicolumn{3}{|c|}{ Gender } \\
\hline Male & 28 & 53.8 \\
\hline Female & 24 & 46.2 \\
\hline \multicolumn{3}{|c|}{ Qualification } \\
\hline Bachelor of nursing & 47 & 90.4 \\
\hline Master in nursing & 5 & 9.6 \\
\hline \multicolumn{3}{|c|}{ Position } \\
\hline Staff nurse & 49 & 94.3 \\
\hline Head nurse & 3 & 5.7 \\
\hline \multicolumn{3}{|c|}{ Years of nursing experience } \\
\hline$\leq 5$ & 35 & 67.3 \\
\hline $6-10$ & 12 & 23.1 \\
\hline$\geq 11$ & 5 & 9.6 \\
\hline \multicolumn{3}{|c|}{ Working unit } \\
\hline Medical ICU & 35 & 44.2 \\
\hline Surgical ICU & 16 & 30.8 \\
\hline $\mathrm{CCU}$ & 13 & 25 \\
\hline \multicolumn{3}{|c|}{ Have a medication administration education program before } \\
\hline Yes & 22 & 42.1 \\
\hline No & 30 & 57.9 \\
\hline
\end{tabular}


Table 2. Levels of nurses' knowledge about the dimensions of medication administration and error during different phases of program intervention $(n=52)$.

\begin{tabular}{cccccc}
\hline \multirow{2}{*}{$\begin{array}{c}\text { IV medication errors } \\
\text { Dimensions }\end{array}$} & & \multicolumn{3}{c}{ Before education Booklet } & After education Booklet \\
\cline { 3 - 6 } & & $\mathrm{n}$ & $\%$ & $\mathrm{n}$ & $\%$ \\
\hline $\begin{array}{c}\text { International patient safety } \\
\text { goals }\end{array}$ & Satisfactory & 28 & 53.8 & 46 & 92.3 \\
\cline { 3 - 5 } $\begin{array}{c}\text { Guidelines of IV } \\
\text { medications administration, }\end{array}$ & Non satisfactory & 24 & 46.2 & 6 & 7.7 \\
$\begin{array}{c}\text { Eight rights of } \\
\text { medication administration }\end{array}$ & Satisfactory & 29 & 58 & 50 & 96.2 \\
\hline
\end{tabular}

Table 3. Knowledge of nurses on eight rights of medication administration and nursing procedures before and after education $(n=52)$.

\begin{tabular}{|c|c|c|c|c|c|}
\hline \multirow{3}{*}{ Right /Nursing Procedures } & \multicolumn{4}{|c|}{ Correct Answers } & \multirow{3}{*}{$\begin{array}{c}\text { Statistical } \\
\text { Analysis } \\
P<0.05\end{array}$} \\
\hline & \multicolumn{2}{|c|}{ Before Education } & \multicolumn{2}{|c|}{ After Education } & \\
\hline & $\mathbf{n}$ & $\%$ & $\mathrm{n}$ & $\%$ & \\
\hline Right Patient & 52 & 100 & 52 & 100 & 1.000 \\
\hline Right Medication & 52 & 100 & 52 & 100 & 1.000 \\
\hline Right Dose & 52 & 100 & 52 & 100 & 1.000 \\
\hline Right Route/Technique & 50 & 96.1 & 52 & 100 & * \\
\hline Right Time & 46 & 88.4 & 51 & 98.1 & * \\
\hline Right Documentation & 41 & 78.8 & 52 & 100 & 0.180 \\
\hline Right Reason & 2 & 3.9 & 32 & 61.5 & 0.000 \\
\hline Right Response & 5 & 9.6 & 27 & 51.9 & 0.000 \\
\hline
\end{tabular}

*Significant $(\mathrm{P}<0.05)$.

As illustrated in Table 4, there was a statistical significant difference related to total knowledge scores of the study subjects about intravenous medication errors where the satisfactory knowledge score pre-test with a mean of $29.3 \pm 0.738$, which was improved to satisfactory mean post-test scores of $43.7 \pm 0.345$ with $\mathrm{P}$ $=0.029$ ).

Table 5 showed the correlation between nurses' knowledge about total medication administration and errors and their demographic characteristics during different phases of program intervention. Statistical analysis showed that there was a statistically significant between age, educational degree, critical units/wards, years of nursing experience and previous medication administration education program of the nurses and their knowledge during different phases of program intervention. On the other hand, there was no significant between the other demographic characteristics of nurses and their knowledge about total medication administration and error such as position $\&$ gender. 
Table 4. Mean score and correlation of the nurses' knowledge about dimensions of medication administration and error during different phases of program intervention $(\mathrm{n}=$ 52).

\begin{tabular}{ccccccc}
\hline Knowledge and Practice & \multicolumn{2}{c}{ Before Education } & \multicolumn{2}{c}{ After Education } & $\begin{array}{c}\text { Statistical Analysis } \\
\text { P }<\text { 0.05 }\end{array}$ \\
\cline { 2 - 5 } Correct Knowledge & Mean & SD & Mean & SD & 0.029 \\
\cline { 2 - 5 } & 29.3 & 0.738 & 43.7 & 0.345 & 0.029 \\
\hline
\end{tabular}

Table 5. Correlation between nurses' knowledge about total medication administration and error and their demographic characteristics during different phases of program intervention $(\mathrm{n}=52)$.

\begin{tabular}{|c|c|c|c|}
\hline \multirow{2}{*}{$\begin{array}{l}\text { Demographic } \\
\text { characteristics }\end{array}$} & \multicolumn{2}{|c|}{ Knowledge Score } & \multirow{2}{*}{$\begin{array}{c}\text { Statistical Analysis } \\
\mathrm{P}<0.05\end{array}$} \\
\hline & Before Education Mean & After Education Mean & \\
\hline \multicolumn{4}{|c|}{ Age } \\
\hline$\leq 25$ & 12.1 & 17.6 & 0.049 \\
\hline $26-30$ & 11.2 & 12.9 & 0.099 \\
\hline$\geq 31$ & 3.6 & 4.1 & 0.86 \\
\hline \multicolumn{4}{|c|}{ Educational degree } \\
\hline Bachelor & 23.1 & 28 & 0.049 \\
\hline Master & 3.1 & 4.6 & 0.05 \\
\hline \multicolumn{4}{|c|}{ Gender } \\
\hline Male & 11.3 & 13.1 & 0.055 \\
\hline Female & 15.9 & 17.7 & 0.042 \\
\hline \multicolumn{4}{|c|}{ Position } \\
\hline Head nurse & 2.1 & 2.5 & 0.049 \\
\hline Staff nurse & 25.2 & 36.1 & 0.061 \\
\hline \multicolumn{4}{|c|}{ Units/wards } \\
\hline Medical ICU & 16.8 & 17.9 & 0.069 \\
\hline Surgical ICU & 10.6 & 16.1 & 0.046 \\
\hline $\mathrm{CCU}$ & 9.4 & 11.2 & 0.049 \\
\hline \multicolumn{4}{|c|}{ Nursing experience } \\
\hline$\leq 5$ & 25.6 & 28.1 & 0.044 \\
\hline $6-10$ & 6.1 & 7.2 & 0.092 \\
\hline$\geq 11$ & 2.2 & 3.1 & 0.09 \\
\hline \multicolumn{4}{|c|}{ Have previous medication administration education program before } \\
\hline Yes & 25.6 & 28.1 & 0.044 \\
\hline No & 9.4 & 11.2 & 0.049 \\
\hline
\end{tabular}




\section{Discussion}

Making sure of patient' security is the highest priority of professionals working in health related facilities, medication errors are known as the most prevalent threat for patient' security that is prevalent in hospital and can be prevented [2] [3] [4]. Among care providers, nurses are considered gatekeeper in reducing the risk of medication errors who are able to detect errors more than any other health care providers due to their direct patient care routine activities and responsibility in administration IV medication to patients [11].

The current study revealed that about more than half of the study subjects hadn't involved in previous medication administration training or education program, where numerous studies have indicated medication errors to be the result of lack of in-service training and inadequate knowledge of nursing graduates, and that a lack of pharmacological knowledge other important cause of medication errors [12] [13].

Furthermore, literature pointed that lack of appropriate guidelines for drug administration to pediatric patients, insufficient knowledge of the medication, insufficient training program and inaccurate or poor reading of prescriptions were cited by nurses as the primary causes of medication errors, in the same context nurses highlighted the need for additional information and/or guidelines regarding drug administration and Regular briefing of pediatric nurses on safe medication administration and proper training of newly engaged nurses have been suggested as routes to reduce medication errors [5] [14].

The situation in most of the hospitals in Palestine is similar, where nurses sided to other health care providers not being given the sufficient attention or the most appropriate tool that would improve their knowledge on medication administration and errors.

Also, the current study results regarding the level of nurses' knowledge about the dimensions of medication administration and error during different phases of program intervention were consistent to those of other researches in this field, where the majority of nurses had low level of knowledge regarding the international patient safety goals, guidelines of medication administration, eight rights of medication administration, then the improved knowledge post the introduction of the educational booklet and related sessions which was statistically significant. Similar results were shown in Elnour study highlighting the important effect of the awareness raising program about medication errors for nursing staff, where increasing pharmacological knowledge of nurses was highly recommended to be as a strategy to reduce serious medication errors later to the significant improvement in the nurses' knowledge on the causes and reporting of medication errors which have been resulted after designing and implementing an educational program to raise the awareness of in-patient nursing staff about medication errors and other medication-related safety issues [15] [16].

Indeed, the importance of education to improve safe medication administration and reduce medication errors is emphasized in the literature. The results of this study are congruent with Bakr, Attala study which revealed that nurses need 
a continuous education program to update their knowledge and practice and pointed that education of the nurses can help reduce medication errors. Also Elliot highlighted that, nurses and nurse managers need to be educated on medication errors and clearly defined working expectations [17] [18].

Furthermore, in a systematic review regarding interventions to reduce medication errors in adult intensive care, showed that multiple interventions revealed statistically significant effects in reduced medication error rates, eight types of such interventions were identified, where four types of these interventions demonstrated reduced medication errors post-intervention: changes in work schedules, modes of education, medication reconciliation and protocols and guidelines [6].

In other systematic review with focus on pediatric medication errors, found that various studies used health care provider education either as main intervention or part of intervention as pediatric medication errors reduction intervention which resulted in an effective impact on reducing medication error [19].

The current study showed a statistically significant correlation between the intensive care nurses age, critical units/wards, years of nursing experience and their knowledge during different phases of program intervention. This result was consistent somehow to what has been documented and explained in literature, where different studies revealed the significant correlation between age of the respondent, nurse's years of experience and the current clinical working area and their improvement of knowledge of nurses about the causes and reporting of medication errors [16] [20] [21] [22] [23] [24]. This association can be clarified by the fact that nurse's main and daily task is medication administration which usually gets used on and tailored with time, frequency and experience. Worthy to mention that also nurses with time and years of work would acquire more knowledge, improved practice and get exposed to various generation and types of medication that would play contributory role in reducing medication administration errors.

The statistical significant association between participant's educational degree and nurses' level of knowledge resulted during pre and post of this intervention study is consistent with different studies which revealed that nurses with higher education level can achieve significant improvement in medication administration knowledge and errors reduction, which could be explained by the gained knowledge and confidence level to defend the consequence of medication administration errors that usually acquired and increase across any learning process [25] [26] [27].

On the other side, this study revealed that intensive care nurses position \& gender were not statistically associated with their level of knowledge about medication administration and errors during the different phases of the study.

\section{Conclusions and Recommendations}

This is the first study in Palestine is to address the intensive care nurses' knowledge regarding medication administration and errors and to identify the effect 
of medication educational intervention on improving nurses' knowledge regarding a crucial patient safety issue and public health priority.

This study emphasized the positive improvements in knowledge of intensive care nurses on intravenous medication administration, as result of the education program, which highlights the urgent need for ongoing training of intensive care nurses concerning safe medication administration in addition to the well-developed educational programs using interactive teaching methods and technology.

The issue of medication errors needs to be brought up into surface through periodic medication error assessment that needs to be reflected on improving the clinical guidelines of medication administration, patient safety and continuous education.

It is highly required to develop institutional protocols, and guidance booklets to provide drug-related information as a part of new nurses' orientation process to ensure quality through reducing errors that may arise during practice.

Designing safe work environment is conducive for patient care delivery and reduce the occurrence of medication administration errors is also recommended.

This study is considered as the first study that investigates the effect of education intervention on the intensive care nurses' knowledge on medication administration errors in Palestine, and calls for further longitudinal researches among Palestinian nurses to tackle the medication administration errors from all perspectives and enhance the safety practice.

Finally, it should be mentioned that the current study had some limitations such as small sample size and conducting the study only in one hospital, therefore it may not be generalized to another setting or other registered intensive care nurses. Also the convenience sample might not reflect the actual population.

It should be noted that similar studies should be carried out on other public and private hospitals; using larger samples to enhance generalizability is highly recommended.

\section{Conflicts of Interest}

The authors declare no conflicts of interest regarding the publication of this paper.

\section{References}

[1] Joint Commission Accreditation Hospital (2014) Hospital National Patient Safety Goals. http://www.jointcommission.org

[2] Agency for Healthcare Research and Quality (2007). http://archive.ahrq.gov/qual/qrdr07.htm

[3] Institute of Medicine (2000) Crossing the Quality Chasm: A New Health System for the 21st Century. National Academy Press, Washington DC.

[4] Bates, D.W., Vanderveen, T., Seger, D.L., Yamaga, C.C. and Rothschild, J. (2005) Variability in Intravenous Medication Practices: Implications for Medication Safety. 
Joint Commission Journal of Patient Safety and Quality, 31, 203-210. https://doi.org/10.1016/S1553-7250(05)31026-9

[5] Abusaad, F. and Etawy, E. (2015) Medication Administration Errors at Children's University Hospitals: Nurses Point of View. Journal of Nursing and Health Science, 4, 51-60. http://www.iosrjournals.org

[6] Manias, E., Williams, A. and Liew, D. (2012) Interventions to Reduce Medication Errors in Adult Intensive Care: A Systematic Review. British Journal of Clinical Pharmacology, 74, 411-423. https://doi.org/10.1111/j.1365-2125.2012.04220.x

[7] Kiekkas, P., Karga, M., Lemonidou, C., Aretha, D. and Karanikolas, M. (2011) Medication Errors in Critically Ill Adults: A Review of Direct Observation Evidence. American Journal of Critical Care, 20, 36-44. https://doi.org/10.4037/ajcc2011331

[8] Wilmer, A., Louie, K., Dodek, P., Wong, H. and Ayas, N. (2010) Incidence of Medication Errors and Adverse Drug Events in the ICU: A Systematic Review. Quality \& Safety in Health Care, 19, e7. https://doi.org/10.1136/qshc.2008.030783

[9] Alsulami, Z., Conroy, S. and Choonara, I. (2013) Medication Errors in the Middle East Countries: A Systematic Review of the Literature. European Journal of Clinical Pharmacology, 69, 995-1008. https://doi.org/10.1007/s00228-012-1435-y

[10] Ministry of Health, Palestinian Health Information Center (PHIC) (2011) Mid-Year Health Report. http://www.lacs.ps/documentsShow.aspx?ATT_ID=4764

[11] Geravandi, S., Moghaddam, F., Sahebalzamani, M. and Javad, M. (2016) Refusing to Report the Medication Errors and Its Effects on Patient's Safety in Razi Teaching Hospital during 2014-2015. Archives of Hygiene Sciences, 5, 214-220.

http://jhygiene.muq.ac.ir

[12] Cheragi, M.A., Manoocheri, H., Nejad, M.E. and Ehsani, S.R. (2013) Types and Causes of Medication Errors from Nurse's Viewpoint. Iranian Journal of Nursing and Midwifery Research, 18, 228-231.

[13] Cloete, L. (2015) Reducing Medication Errors in Nursing Practice. Nursing Standard, 29, 50-59. https://doi.org/10.7748/ns.29.20.50.e9507

[14] Toruner, E.K. (2012) Causes, Reporting, and Prevention of Medication Errors from a Pediatric Nurse Perspective. Australian Journal of Advanced Nursing, 29, 28-35.

[15] Johari, H., Shamsuddin, F., Idris, N. and Hussin, A. (2013) Medication Errors among Nurses in Government Hospital. IOSR Journal of Nursing and Health Science (IOSR-JNHS), 1, 18-23. https://doi.org/10.9790/1959-0121823

[16] Elnour, et al. (2008) The Nine Rights of Medication Administration: An Overview. British Journal of Nursing, 19, 300-305. https://doi.org/10.12968/bjon.2010.19.5.47064

[17] Bakr, M. and Attaha, H. (2012) Evaluation of Drug Administration Errors in a Teaching Hospital. BMC Health Services Research, 12, 60. https://doi.org/10.1186/1472-6963-12-60

[18] Elliott, M. and Liu, Y. (2010) The Nine Rights of Medication Administration: An Overview. British Journal of Nursing, 19, 300-305. https://doi.org/10.12968/bjon.2010.19.5.47064

[19] Rinke, L., Bundy, G., Velasquez, A., Rao, S., Zerhouni, Y., Lobner, K., Blanck, F. and Miller, R. (2014) Interventions to Reduce Pediatric Medication Errors: A Systematic Review. American Academy of Pediatrics, 134, 338-360.

[20] Feleke, S.A., Mulatu, M.A. and Yesmaw, Y.S. (2015) Medication Administration Error: Magnitude and Associated Factors among Nurses in Ethiopia. BMC Nursing, 14, 53. https://doi.org/10.1186/s12912-015-0099-1 
[21] Fahimi, F., Ariapanah, P., Faizi, M., Shafaghi, B., Namdar, R. and Ardakani, M. (2008) Errors in Preparation and Administration of Intravenous Medications in the Intensive Care Unit of a Teaching Hospital: An Observational Study. Australian Critical Care, 21, 110-116. https://doi.org/10.1016/j.aucc.2007.10.004

[22] Westbrook, J., Rob, M., Woods, A. and Parry, D. (2011) Errors in the Administration of Intravenous Medications in Hospital and the Role of Correct Procedures and Nurse Experience. BMJ Quality and Safety, 20, 1027-1034.

https://doi.org/10.1136/bmjqs-2011-000089

[23] Abualrab, M.L. and Al-Zaru, M. (2008) Errors in the Administration of Intravenous Medication in Saudian Hospitals. Journal of Clinical Nursing, 16, 1839-1847. https://doi.org/10.1111/j.1365-2702.2007.01834.x

[24] Fulbrook, P. and Albarran, J. (2012) Nurses' Medication Work: What Do Nurses Know? Journal of Clinical Nursing, 19, 3218-3226. https://doi.org/10.1111/j.1365-2702.2010.03249.x

[25] Armutlu, M., Foley, M., Surette, J., Belzile, E. and McCusker, J. (2008) Survey of Nursing Perceptions of Medication Administration Practices, Perceived Sources of Errors and Reporting Behaviors. Healthcare Quarterly, 11, 58-65. https://doi.org/10.12927/hcq.2008.19651

[26] Cousins, D., Sabatier, B., Begue, D., Schmitt, C. and Hoppe-Tichy, T. (2005) Medication Errors in Intravenous Drug Preparation and Administration: A Multicenter Audit in the UK, Germany and France. Quality and Safety in Health Care, 14, 190-195. https://doi.org/10.1136/qshc.2003.006676

[27] Bifftu, B.B., Dachew, B.A., Tiruneh, B.T. and Beshah, D.T. (2015) Medication Administration Error Reporting and Associated Factors among Nurses Working at the University of Gondar Referral Hospital, Northwest Ethiopia. BMC Nursing, 15, Article No. 43. https://doi.org/10.1186/s12912-016-0165-3 